\title{
Onset rivalry: the initial dominance phase is independent of ongoing perceptual alternations
}

\author{
Jody Stanley ${ }^{1}$, Jason D. Forte ${ }^{1}$, Patrick Cavanagh ${ }^{2,3}$ and Olivia Carter ${ }^{1}$ \\ 1 Psychological Sciences, University of Melbourne, Parkville, VIC, Australia \\ 2 Department of Psychology, Harvard University, Cambridge, MA, USA \\ ${ }^{3}$ Laboratoire Psychologie de la Perception, Université Paris Descartes, Paris, France
}

Edited by:

Naotsugu Tsuchiya, RIKEN, Japan

Reviewed by:

Randolph Blake, Seoul National University, South Korea

Jan Brascamp, Vanderbilt University, USA

\section{*Correspondence:}

Jody Stanley, Psychological Sciences, University of Melbourne, Parkville,

VIC 3010, Australia.

e-mail: jodys@unimelb.edu.au
Binocular rivalry has been used to study a wide range of visual processes, from the integration of low-level features to the selection of signals that reach awareness. However, many of these studies do not distinguish between early and late phases of rivalry. There is clear evidence that the "onset" stage of rivalry is characterized by stable, yet idiosyncratic biases that are not evident in the average dominance of sustained rivalry viewing. Low-level stimulus features also have robust effects in the onset phase that are not seen in sustained rivalry, suggesting these phases may be driven at least partly by different neural mechanisms. The effects of high-level cognitive and affective factors at onset are less clear but also show differences from their effects in sustained viewing. These findings have important implications for the interpretation of any rivalry experiments using brief presentation paradigms and for understanding how the brain copes with binocular discrepancies in natural viewing conditions in which our eyes constantly move around an ever-changing environment. This review will summarize current research and explore the factors influencing this "onset" stage.

Keywords: binocular rivalry, perceptual bias, vision, awareness, ambiguity, visual field, suppression, bistable stimuli
When dissimilar images are presented respectively to the two eyes, an initial fusion of the two scenes (Wolfe, 1983) is rapidly replaced by the perception of only one of the two images. If the observer continues to view these images, conscious perception will alternate between the two monocular percepts indefinitely (Wheatstone, 1838; Blake and Logothetis, 2002). Such "binocular rivalry" occurs without any change to the stimuli themselves. This disparity between unchanging stimuli and fluctuating conscious perception has provided an important tool for studying a vast range of neural processes, from early visual features such as luminance (Kaplan and Metlay, 1964), contrast (Mueller and Blake, 1989), and motion (Blake et al., 2003), to visual processing in psychiatric populations (Miller et al., 2003; Nagamine et al., 2007), and the neural correlates of conscious awareness (Logothetis, 1998; Lin and He, 2009). While binocular rivalry is a psychophysical paradigm, it has been used in conjunction with a variety of brain imaging (Tong and Engel, 2001; Haynes et al., 2005; Lee et al., 2005) and electrophysiological measures (Leopold and Logothetis, 1996) that have all contributed to providing considerable information about the associated brain mechanisms involved in visual processing and awareness.

Until recently, it was assumed that, subsequent to fusion, all rivalry was guided by a common process (or set of processes). Recent studies have now demonstrated that the initial properties of rivalry differ significantly from those seen over extended periods and may, in fact, be determined by distinct mechanisms. Most notable is the striking degree of stability and predictability in perceptual dominance at rivalry onset, which stands in complete contrast to the stochastic nature of perceptual switches that is often considered a fundamental property of sustained perceptual rivalry viewing (Fox and Herrmann, 1967; Kim et al., 2006; van Ee, 2009). This paper will review recent results concerning the different factors that affect onset rivalry and the differences between this onset phase and sustained rivalry. This review will also briefly consider the implications for current perceptual rivalry research.

\section{ONSET BIASES ACROSS THE VISUAL FIELD}

One of the most striking characteristics of onset rivalry is the existence of strong and stable localized biases that vary across the visual field both within and between subjects (Carter and Cavanagh, 2007; Stanley et al., 2011; see Figure 1). For example, one area of the visual field may have a strong onset rivalry bias, so that the same target is seen first on almost every trial. In another area of the visual field, however, the opposite target might be almost exclusively dominant at onset. This onset bias can only be partly explained by monocular dominance, and despite the idiosyncratic nature of the pattern of onset bias across the visual field, it is found to be stable across weeks within an individual. Such biases toward dominance of a given target were not seen during subsequent alternations in sustained rivalry (Carter and Cavanagh, 2007).

Onset rivalry also differs from sustained rivalry dominance periods in respect to the effects of equating stimulus strength. It is well established that changing the contrast, luminance, or spatial frequency of one rivaling target will reliably increase the 

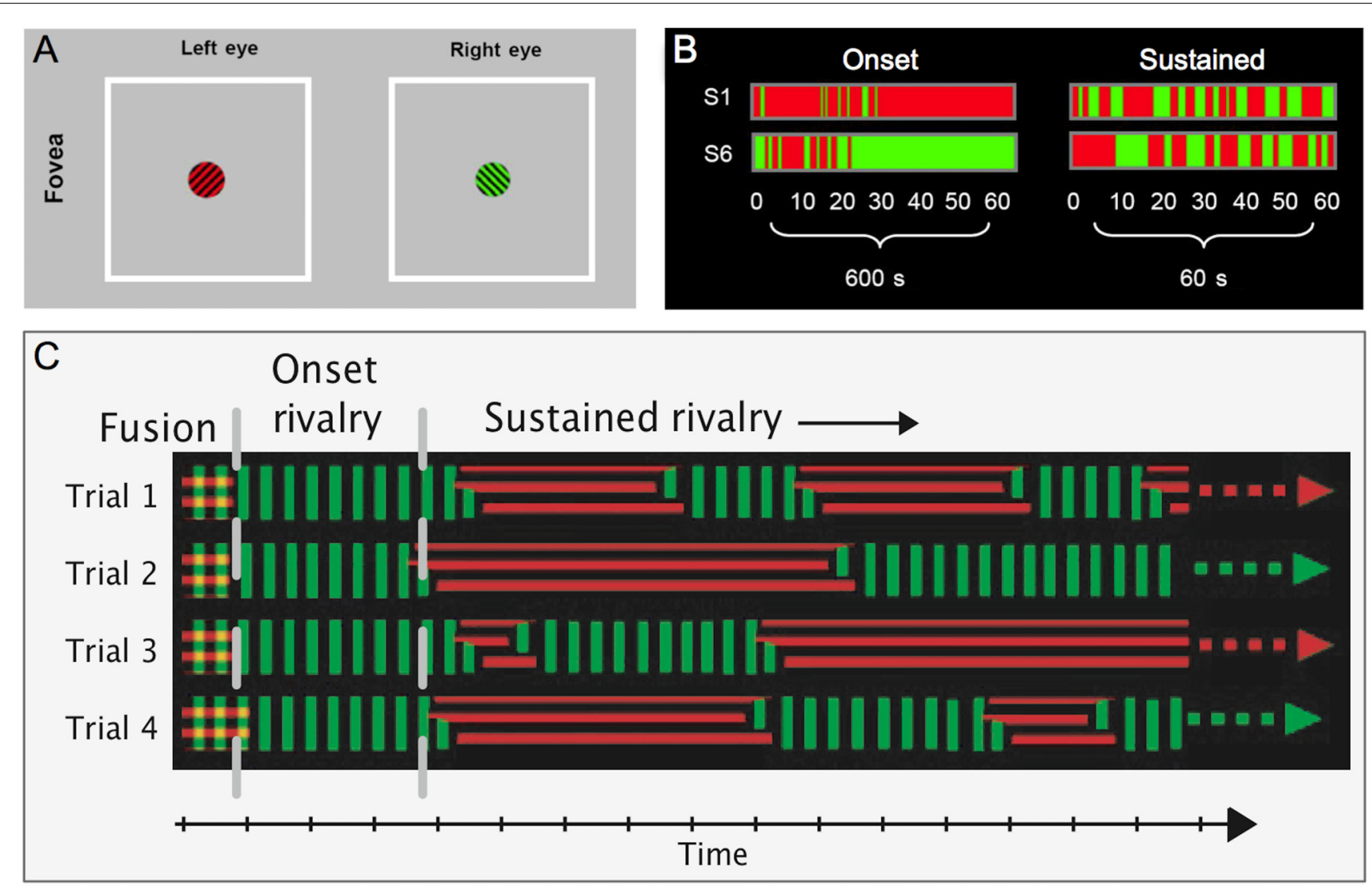

FIGURE 1 | Onset biases: (A) Examples of stimuli used to assess onset rivalry in the fovea. Orthogonal green and black, and red and black gratings were presented to the fovea for 60 presentations of $1 \mathrm{sec}$ (with $9 \mathrm{sec}$ of stimulus removal), or $60 \mathrm{sec}$ of continuous presentation. (B) Data from two subjects show consistent, but opposite onset biases during the 60 intermittent $1 \mathrm{sec}$ presentations (over $600 \mathrm{sec}$ ). In the sustained $60 \mathrm{sec}$ presentation, however, average dominance durations show no bias (modified from Carter and

Cavanagh, 2007). (C) A schematic illustrating the time course of rivalry over four trials depicts a consistent bias toward one target at onset, while dominance at a given time during the rest of the sustained viewing period is random proportion of dominance of that target over a sustained viewing period, and conversely, equating the stimuli will reduce these biases (Levelt, 1967). Onset rivalry is also strongly biased toward a target with greater stimulus strength (Chong and Blake, 2006; Song and Yao, 2009). Unlike sustained rivalry, however, the initial presentation of balanced stimuli will not necessarily result in an equal likelihood of either target gaining dominance at onset. At the onset of rivalry, strong and consistent onset biases remain after minimizing the luminance and contrast differences by calibrating the stimuli separately for each individual and in each location of the visual field (Stanley et al., 2011; see Figures 2A-C). The persistence of the localized onset bias suggests that other endogenous factors determine onset dominance. For example, the fact that swapping the eye of presentation of the calibrated images has led to complete reversal of perceived color in some areas, suggests that regions of monocular dominance may also have an influence on onset rivalry (Stanley et al., 2011).

\section{LOW-LEVEL EFFECTS ON ONSET DOMINANCE}

The influence of monocular dominance on the initial dominance phase in rivalry has been reported previously. In an early study on color rivalry, Crovitz and Lipscomb (1963) presented split and full color red and green fields for $100 \mathrm{~ms}$ in rivaling conditions. They found that observers most commonly reported a percept corresponding to the colors presented in the temporal visual fields (Crovitz and Lipscomb, 1963). Similarly, Leat and Woodhouse (1984) showed that flashed stimuli, which engage only the onset phase of rivalry, showed a dominance bias as great as approximately $5-95 \%$ in some individuals compared to continuous presentations, which were generally quite balanced with approximately $50 \%$ dominance. Although dominance biases for flashed and continuous presentations were correlated, the authors concluded that the difference in the range of bias indicated that flashed stimuli were more sensitive to ocular dominance by a factor of 10-20. Some observers showed enhanced dominance of the nasal retinas and others of the temporal retinas, but either pattern of dominance tended to be consistent within one-half of the visual field (Leat and Woodhouse, 1984). Although there was very little evidence of dominance bias during sustained viewing, more recent studies have shown that visual field location can affect the overall rate of switching in sustained rivalry (Chen and He, 2003). As these onset studies show, initial dominance is particularly sensitive to zones of monocular dominance that exist across the visual field. However, the substantial individual difference in the pattern of 

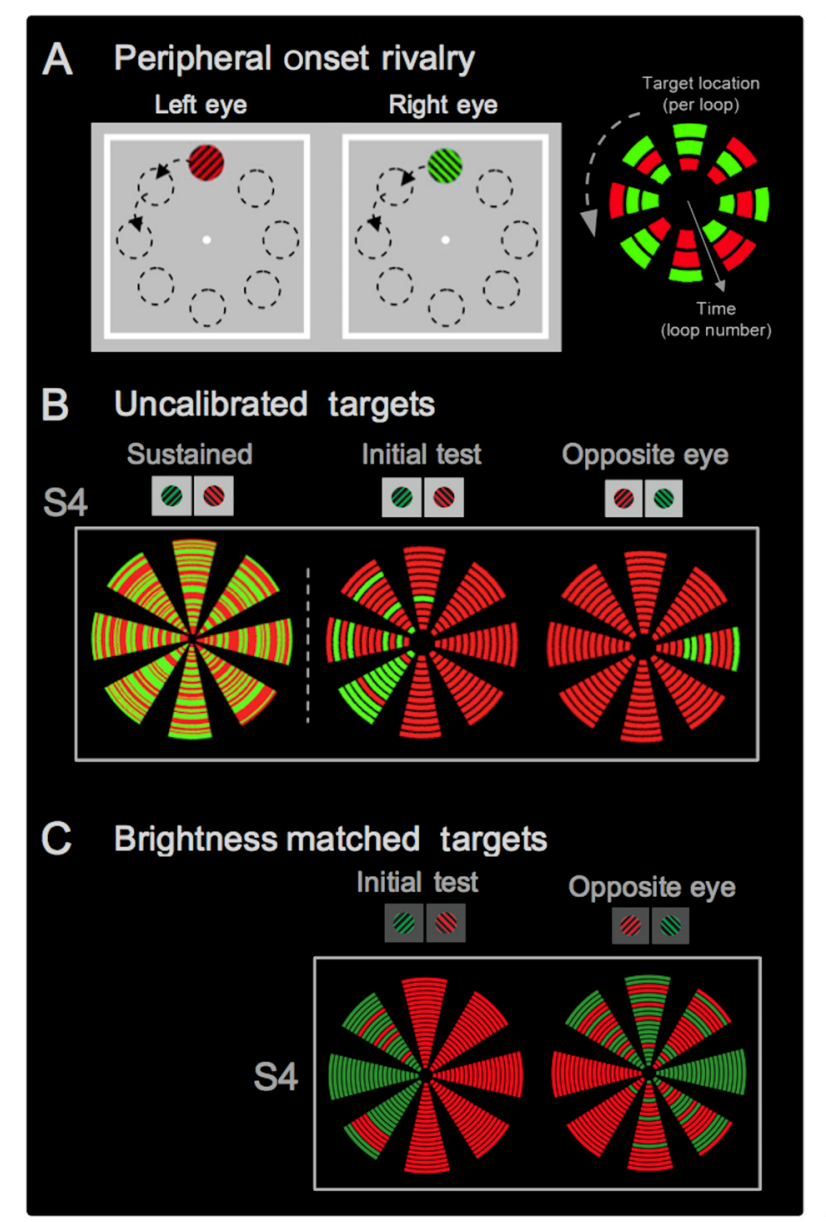

FIGURE 2 | Idiosyncrasies of onset rivalry across the visual field. (A) Peripheral stimuli used to test location specific onset biases within an individual. Orthogonal gratings were presented to the left and right eye, in eight locations of the visual field. The black dotted outlines of these locations are for illustration only and were not part of the experimental display. To the right is a schematic of the data presentation used in (B,C). Each block of color represents the reported perceptual dominance at an individual stimulus onset (the eight wedges represent the eight locations and time is illustrated with the inner and outer locations representing the first and last presentations respectively. (B) On the left, data from sustained rivalry presentation in the periphery shows no dominance bias of either target (each loop represents $1 \mathrm{sec}$ of presentation during $60 \mathrm{sec}$ of sustained rivalry). In contrast the two right panels show that during onset rivalry the pattern of biases within a single person vary depending on the location of the visual field and the eye of presentation (individual data from S4 in Carter and Cavanagh, 2007). (C) Data

\section{Peripheral motion rivalry}
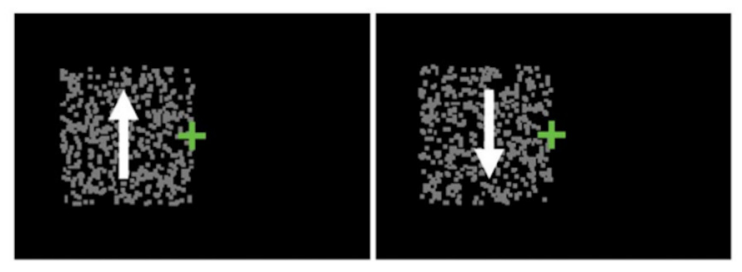

E
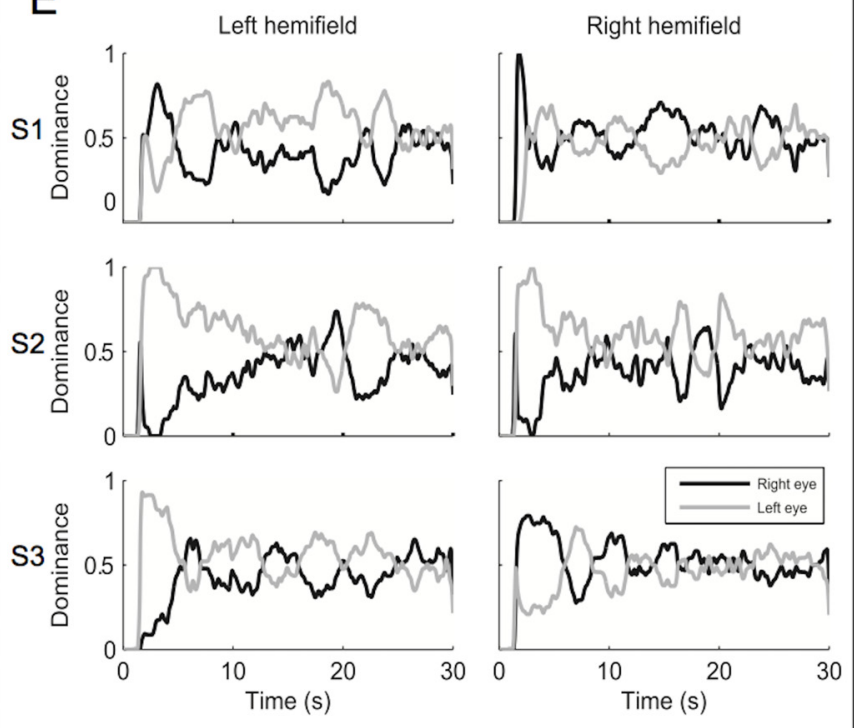

from the same observer shows that when brightness is matched in each location onset biases remain, which is representative of the results seen across participants. Though there are still clear biases, some change in the pattern is evident after balancing the targets. For example, some locations have an exaggerated bias while others have less complete bias, and in some cases the preferred color has switched. With the calibrated rivalry targets, some locations show a complete reversal of onset bias when targets are presented to the opposite eyes, suggesting influence of monocular dominance (individual data from S4 in Experiment 1 of Stanley et al., 2011). (D) Ambiguous opponent motion stimuli presented to the right or left of fixation induces similar idiosyncratic onset biases (modified from Figure 1 in Kalisvaart et al., 2011). (E) At the onset of sustained presentation, S1 and S2 showed right and left eye bias, respectively, and S3 showed temporal field bias. However, subjects displayed no dominance bias during later periods of the presentation (modified from Figure 3 in Kalisvaart et al., 2011). ocular dominance seen with a range of rivalry stimuli (Kalisvaart et al., 2011; Stanley et al., 2011), and the fact that hemifield effects are not always seen if the rivaling targets are not carefully calibrated (Carter and Cavanagh, 2007) shows that monocular dominance cannot fully explain the biases in onset rivalry (see Figure 2).

The finding that visual field effects are revealed after individually equating brightness in each eye suggests that there is an interaction between endogenous biases and influences that originate from the stimuli themselves. For example, influences from ocular dominance appear to interact with hypersensitivity at onset to differences in stimuli strength. With respect to stimulus strength, onset dominance appears to be particularly sensitive to small imbalances in luminance contrast (Chong and Blake, 2006; Song and Yao, 2009; see Figure 3). Onset dominance may be so sensitive to contrast differences that variability in spectral sensitivity between individuals and across the retina (Albrecht et al., 2002) may be sufficient to influence the pattern of onset bias (Stanley et al., 2011). Other studies have shown that both exogenous (Mitchell et al., 2004; Chong and Blake, 2006) and endogenous (Chong and Blake, 2006) attention have a greater influence at onset than on average dominance during sustained presentation. While attention is often thought of as a high-level 


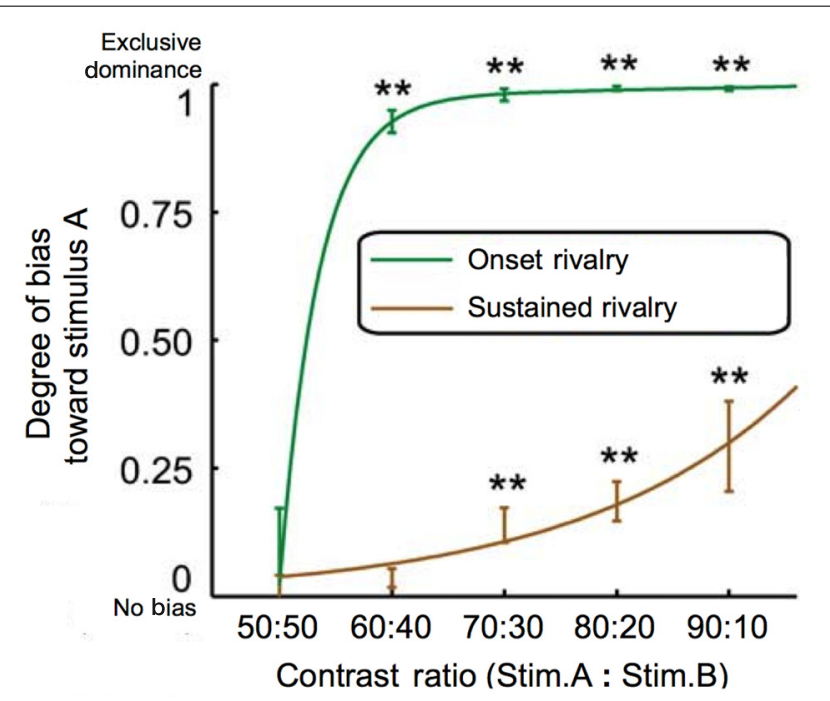

FIGURE 3 | Onset dominance is more sensitive to contrast imbalances than sustained dominance. By comparing stimuli with varying contrast imbalances (ranging in contrast ratios of 50:50 to 90:10), it was found that small imbalances are sufficient to cause exclusive dominance of the higher-contrast image at onset. In the case of sustained rivalry, however, exclusive dominance was never achieved even at the greatest contrast imbalance of 90:10 (modified from Figure 2B in Song and Yao, 2009).

effect, the authors suggest that their observed effect of attention may have, in fact, been mediated by an increase in apparent contrast (Chong and Blake, 2006). This interpretation was based on the finding that directing attention to a grating has been claimed to boost the apparent contrast between 30 and 70\% (Carrasco et al., 2004).

The degree of location specificity observed across the visual field at rivalry onset suggests the endogenous biases are closely tied to the position of the image on the retina. Consistent with this view, it was shown that when rivaling images were displaced on the retina - through saccades or through shifting the stimulus itselfthe dominant percept after the shift was systematically related to the initial onset bias displayed by each subject (Kalisvaart et al., 2011). These findings suggest that engaging new areas of the retina will again recruit onset processes. Interestingly, although this result was observed after both a saccade and a stimulus jump, the relationship between percept dominance and onset bias was weaker after a saccade. Despite both conditions engaging new areas of the retina, an active saccade appeared to diminish the effects of onset rivalry bias. There are currently no data available to determine the basis of this attenuation of the onset bias, however, possible causes could range from other relatively low-level effects beyond retinal signals to such high-level influences as saccadic remapping (Bays and Husain, 2007; Cavanagh et al., 2010).

\section{HIGH-LEVEL EFFECTS ON ONSET DOMINANCE}

Although most studies of the onset stage of rivalry have used features that are processed by the early visual system, there are a few studies that have investigated high-level, cognitive influences at rivalry onset. A recent study has shown that the utility of a particular percept can bias initial dominance in rivalry. When perception of one orientation of rivaling Gabor patches allowed observers to complete a search task more efficiently, observers were more likely to perceive that orientation as the initial percept, even though they were unaware of its utility. This bias continued even when the grating no longer provided any advantage to the task. Surprisingly, the influence of the learned utility of the grating orientation was limited exclusively to the onset phase and had no effect on subsequent dominance durations (Chopin and Mamassian, 2010). Denison etal. (in press) have shown that when rivalry of dichoptic orthogonal gratings is preceded by the predictive context of non-rivaling gratings in perceived rotation, there is a bias at the onset of rivalry toward the orientation that would match the next presentation in the rotation sequence.

Two other studies have investigated differences between images that influence psychological attributes like emotional saliency and show intriguing and somewhat contradictory effects with respect to initial dominance. The first study by Sheth and Pham (2008) used emotionally arousing images. These images showed no effect at the onset of rivalry, though the emotional content of the images affected overall percentage of dominance during sustained rivalry (Sheth and Pham, 2008). This finding suggests limited involvement at onset from higher areas where visual signals are coupled with emotional cues. However, a second study by Gray et al. (2009) found that an observer's anxiety level had a strong effect on initial dominance of emotional faces, and was associated with an increased tendency to perceive angry faces and decreased tendency to perceive happy faces. Such results suggest that the relatively high-level factors of an observer's emotional state and the emotional saliency of a rivaling target can affect rivalry during the onset stage. As this study only examined effects at the onset of rivalry, it is unclear whether heightened anxiety would continue to modulate an average dominance bias toward emotional stimuli over longer stimulus durations. Further research is needed to clarify the role of emotion and arousal in onset rivalry as distinct from their role in sustained rivalry.

\section{ONSET BIASES USING OTHER AMBIGUOUS STIMULI}

Although the onset stage of perceptual rivalry has been studied predominately using binocular rivalry stimuli, it is also important to note that disparate effects and biases at onset are also present when viewing other types of ambiguous stimuli. Dobbins and Grossmann (2010) presented rotating Necker cubes at various areas of the visual field and found that a cube rotating around a vertical axis was seen as viewed from above at onset more than $90 \%$ of the time, while a cube rotating around a horizontal axis was more likely to be interpreted as being viewed from the right side if it was placed on the left side of the screen. The authors suggest real-world asymmetries (e.g., boxes are more likely to be seen from above) are encoded in the visual system and this inherent expectation is particularly influential at onset (Dobbins and Grossmann, 2010).

The bistable auditory streaming paradigm (Pressnitzer and Hupé, 2006; Snyder et al., 2009) and plaid motion rivalry (Hupé and Rubin, 2003) have also been shown to have strong onset biases. In both cases the "coherent" percept of the visual 
Table 1 | Studies investigating onset dominance in binocular rivalry.

\begin{tabular}{|c|c|c|}
\hline Study & Onset effect & Sustained effect* \\
\hline \multirow{4}{*}{ Visual field location } & $\begin{array}{l}\text { Dominance of the temporal hemifields demonstrated using } \\
\text { full-field color stimuli (Crovitz and Lipscomb, 1963) }\end{array}$ & Not assessed in Crovitz and Lipscomb (1963) \\
\hline & $\begin{array}{l}\text { Hemifield dominance shown using gratings presented along } \\
\text { horizontal midline, however, the dominant hemifield (temporal/ } \\
\text { nasal) varied between observers (Leat and Woodhouse, 1984) }\end{array}$ & $\begin{array}{l}\text { No dominance bias in hemifields observed (Leat and } \\
\text { Woodhouse, 1984) }\end{array}$ \\
\hline & $\begin{array}{l}\text { Colored grating patches presented in the periphery caused strong } \\
\text { onset biases that varied between individuals and across locations } \\
\text { within an individual (Carter and Cavanagh, 2007). Areas of temporal } \\
\text { hemifield dominance only became evident after matching each } \\
\text { location for perceived brightness (Stanley et al., 2011) }\end{array}$ & $\begin{array}{l}\text { No localized bias observed when brightness was not } \\
\text { matched (Carter and Cavanagh, 2007). Not assessed in } \\
\text { Stanley et al. (2011) after brightness matching }\end{array}$ \\
\hline & $\begin{array}{l}\text { Onset bias shown for motion, house/face, and grating binocular } \\
\text { rivalry. Individual observers exhibited right eye, left eye, or temporal } \\
\text { hemifield bias, but no nasal hemifield bias (Kalisvaart et al., 2011) }\end{array}$ & $\begin{array}{l}\text { No bias observed after } 10 \text { sec of sustained viewing } \\
\text { (Kalisvaart et al., 2011) }\end{array}$ \\
\hline Eye movements & $\begin{array}{l}\text { Retinal image shift renewed onset bias, but more so for stimulus } \\
\text { shifts than saccades (Kalisvaart et al., 2011) }\end{array}$ & $\begin{array}{l}\text { Not assessed as part of image shift experiment } \\
\text { (Kalisvaart et al., 2011) }\end{array}$ \\
\hline \multirow[t]{2}{*}{ Contrast } & $\begin{array}{l}\text { Small imbalances in contrast caused exclusive dominance of } \\
\text { higher-contrast image (Song and Yao, 2009) }\end{array}$ & $\begin{array}{l}\text { Average dominance of a target increased gradually with } \\
\text { larger contrast imbalances up to maximum imbalance ratio } \\
\text { of } 90: 10 \text { but exclusive dominance was not achieved (Song } \\
\text { and Yao, 2009) }\end{array}$ \\
\hline & $\begin{array}{l}\text { Minimizing contrast differences by matching brightness in each } \\
\text { location for each observer unmasked other endogenous biases } \\
\text { (Stanley et al., 2011) }\end{array}$ & Not assessed in Stanley et al. (2011) \\
\hline \multirow[t]{2}{*}{ Attention } & $\begin{array}{l}\text { Both exogenous (Mitchell et al., 2004; Chong and Blake, 2006) and } \\
\text { endogenous (Chong and Blake, 2006) attention increased onset } \\
\text { dominance of attended grating }\end{array}$ & $\begin{array}{l}\text { Not assessed in Mitchell etal. (2004) or Chong and Blake } \\
\text { (2006) }\end{array}$ \\
\hline & $\begin{array}{l}\text { Effect of attention counteracted by reducing contrast of } \\
\text { attention-boosted target } 0.3 \text { log-units (Chong and Blake, 2006) }\end{array}$ & Not assessed in Chong and Blake (2006) \\
\hline \multirow[b]{2}{*}{ Task relevance } & $\begin{array}{l}\text { Onset bias toward task-relevant grating; bias persisted even when } \\
\text { grating was no longer task-relevant (Chopin and Mamassian, 2010) }\end{array}$ & $\begin{array}{l}\text { No increase in average dominance of task-relevant grating } \\
\text { (Chopin and Mamassian, 2010) }\end{array}$ \\
\hline & $\begin{array}{l}\text { A spinning Necker cube was more likely to be seen as viewed from } \\
\text { above when rotating on a vertical axis, and from the right when } \\
\text { rotating on a horizontal axis on the left side of the screen. Authors } \\
\text { suggest encoding of ecological relevance (Dobbins and } \\
\text { Grossmann, 2010) }\end{array}$ & $\begin{array}{l}\text { Some observers exhibited average dominance bias during } \\
\text { 15-s presentation, though slow switch from biased } \\
\text { dominance at onset may account for this result (Dobbins and } \\
\text { Grossmann, 2010) }\end{array}$ \\
\hline Context & $\begin{array}{l}\text { Onset bias toward grating orientation that would match the next } \\
\text { presentation in a preceding perceived rotation sequence (Denison } \\
\text { et al., in press) }\end{array}$ & Not assessed in Denison etal. (in press) \\
\hline \multirow[b]{2}{*}{ Emotional salience } & $\begin{array}{l}\text { No significant bias toward emotionally arousing images (Sheth and } \\
\text { Pham, 2008) }\end{array}$ & $\begin{array}{l}\text { Greater average dominance of emotionally arousing images } \\
\text { after } 15 \text { sec of viewing (Sheth and Pham, 2008) }\end{array}$ \\
\hline & $\begin{array}{l}\text { Observer's anxiety level influences onset dominance of emotional } \\
\text { faces: greater tendency to perceive angry faces and less tendency } \\
\text { to perceive happy faces (Gray et al., 2009) }\end{array}$ & Not assessed in Gray et al. (2009) \\
\hline
\end{tabular}

*Sustained effects reported here only refer to results obtained in the corresponding onset studies listed. Countless studies have been conducted using sustained rivalry, many of which show effects from the factors listed in this table, however, it is sometimes difficult to compare across paradigms, as multiple stimulus and procedural properties are likely to vary between studies. A number of detailed reviews of sustained rivalry have been published previously (Blake and Logothetis, 2002; Long and Toppino, 2004; Tong etal., 2006; Blake and Wilson, 2011). Also not listed in the table are studies that use an intermittent presentation paradigm. For a review of these studies see Pearson and Brascamp (2008).

plaid or single auditory stream is almost exclusively found to dominate at stimulus onset (Hupé and Rubin, 2003; Pressnitzer and Hupé, 2006; Snyder et al., 2009). While we are not aware of any study that has specifically investigated onset dominance during tactile rivalry, it has been reported that proprioceptive and tactile stimuli known to induce illusory motion reversals show exclusive dominance of the veridical motion direction at stimulus onset and will only alternate in a more balanced fashion after sustained stimulus presentation
(Holcombe and Seizova-Cajic, 2008). A summary of current literature investigating the distinct onset phase of rivalry can be found in Table 1.

\section{ONSET DOMINANCE DISTINCT FROM PERCEPTUAL MEMORY}

As the focus of this review is the factors influencing perceptual dominance at stimulus onset, it is important to also clarify how 
onset dominance relates to the influence of perceptual memory demonstrated by intermittent stimulus paradigms (for review see Pearson and Brascamp, 2008). When rivaling images are presented and removed every few seconds, percept switching slows and dominance can appear to stabilize, with each new presentation of rivalry more likely to display the same dominant percept as the one last seen (Leopold et al., 2002). Importantly, while dominance periods lengthen considerably under these conditions, perceptual dominance does continue to alternate, maintaining approximately equal average dominance between the two possible percepts (Brascamp et al., 2009).

This pattern of dominance is quite distinct from the localized onset biases that are the focus of the current review. When stimuli are presented intermittently in the same location of the visual field, the initial dominance at each repeated presentation is most likely to be consistent with the perceptual state during the last presentation (Pearson and Brascamp, 2008). This "perceptual memory trace" appears to build up and disappear over each stimulus presentation and removal period such that it takes multiple presentation cycles for a perceptual reversal to be triggered (Brascamp et al., 2008; Pastukhov and Braun, 2008). In contrast, in the absence of perceptual memory-with greater than 10-s intervals between stimulus presentations (Carter and Cavanagh, 2007) or after stimulus shifts (Kalisvaart et al., 2011; Stanley et al., 2011)_onset biases for an individual are stable across weeks. Furthermore, in the relatively rare event that onset dominance does switch to the "non-predominant" target, the switch does not stabilize consistent with a "memory" of the new target, but quickly reverts back to the target that is most typically dominant in that area on subsequent presentations (Carter and Cavanagh, 2007; Stanley et al., 2011).

Based on the current literature, therefore, there is little doubt that onset rivalry and perceptual memory are clearly distinct phenomena. It is less clear however, whether the two are completely independent. One alternative is that perceptual history is simply one factor, like monocular dominance, that can sometimes have a powerful effect at rivalry onset. Given that onset rivalry is evident with a $1 \mathrm{sec}$ on, $9 \mathrm{sec}$ off paradigm (Carter and Cavanagh, 2007; Stanley et al., 2011) and perceptual memory is typically observed when stimuli are on for $3 \mathrm{sec}$ and off for $5 \mathrm{sec}$ (Leopold et al., 2002), one would expect that the relative distinction between the two phenomena would be reduced by decreasing or increasing the interval between stimulus onsets respectively. While it is clear that perceptual memory cannot account for the onset biases observed after longer interstimulus intervals, more research is needed to tease apart these two paradigms. At least one study has demonstrated a degree of interaction between endogenous onset biases and non-local perceptual memory. Knapen et al. (2009) has shown that the degree to which perceptual memory can transfer to peripheral locations can be increased if the stimulus is adjusted to account for local onset biases. Future research into onset rivalry or perceptual memory should therefore guard against confounding of the two paradigms - repeated trials intended to examine onset rivalry may begin to engage perceptual memory, and onset biases may also interact to weaken the influence of perceptual memory during intermittent presentations.

\section{MODELS OF RIVALRY}

A few models of binocular rivalry have been extended to include the role of perceptual memory when stimuli are first presented after a blank period (Noest et al., 2007; Wilson, 2007). So far, however, these models have only focused on the initial dominance in an intermittent presentation paradigm as described above, and do not yet account for the endogenous biases and sensitivity that are apparent when stimuli are first presented to the retina and no perceptual history is available. These models do predict that even very small input imbalances can dictate dominance in intermittent presentation (Noest et al., 2007; Klink et al., 2008). However, whether this aspect of the model will be able to fully explain the sensitivities of onset dominance has yet to be explicitly explored. Other commonly cited models of rivalry focus primarily on the stochastic alternation of percepts during sustained viewing, and describe mutual inhibition and adaptation at several levels of the visual hierarchy (Tong et al., 2006; Sterzer and Rees, 2008), or refer to Bayesian (Sundareswara and Schrater, 2008), predictive coding (Hohwy et al., 2008), or random and noise effects (Brascamp etal., 2006; Kim et al., 2006; Moreno-Bote et al., 2007). Such models of traditional rivalry do not yet distinguish between the mechanisms underlying the onset phase and those that drive subsequent switching. They also do not attempt to explain the consistency of the strong biases seen at onset, or the variation in these biases observed across the visual field. Such findings suggest that models of rivalry may need to take into account the particular physiology of an individual observer as well as perceptual history.

A formal model of onset rivalry is yet to be proposed. However, the biases and heightened sensitivities at the onset of rivalry might be partly explained by a model in which slight differences in signal strength result in latency differences between information coming from the same area of each eye. These disparities may allow one percept to "win the race," either by reaching a relevant anatomical destination earlier or by attaining a required activation threshold more quickly. In such a race model, the winning signal will then become the exclusive conscious percept until the competing neural representation is similarly established. It is frequently proposed that rivalry depends on a degree of mutual inhibition that builds up over time between competing neural representations (for review see Blake and Logothetis, 2002). It would follow, therefore, that a perceptual switch could not begin until both neural representations had indeed become established. If this model were true, any small imbalances in the speed of the incoming signals would only be relevant at the point of stimulus onset, and would cease to be relevant once the competitive processes dictating sustained rivalry switching had begun. Of course, more focused research is needed to determine the neural areas or physiological processes that govern the initial processing of ambiguous visual input, such as pinpointing the "destination" or mechanisms within the brain that allow such conscious perception to first be decided. Further research is also required to determine how the mechanisms associated with onset rivalry relate to those involved in the initial fusion period reported with very brief $(100 \mathrm{~ms})$ presentations or to those associated with sustained rivalry paradigms. 
It may turn out that onset and sustained rivalry involve identical mechanisms that differ in the degree to which they are influenced by certain factors. An extreme alternative that should also be considered, however, is that onset rivalry is closer to other forms of visual suppression such as "masking" (Breitmeyer, 1984). For example, the extent to which the suppressed image is represented in visual cortical regions might either be considerably reduced or completely distinct from the neural representations of suppression during sustained rivalry conditions. Although electroencephalography studies have been conducted using intermittent paradigms (for review see Pitts and Britz, 2011), no brain imaging or electrophysiological study of onset rivalry has been conducted to date. However, intracranial recording from early visual cortex shows the representations of suppressed stimuli which are seen during sustained rivalry presentation are not observable during the initial period of perceptual suppression after stimulus onset (personal communication with Tsuchiya-see also Tsuchiya et al., 2011). If the level of suppression seen at stimulus onset is indeed greater than the suppression associated with sustained rivalry, this may have implications for studies using continuous flash suppression (CFS). In CFS the image in one eye can be suppressed for minutes at a time by presenting the other eye with constantly changing, contour rich, and high contrast stimulation (Tsuchiya and Koch, 2005). The non-dominant image in CFS is also suppressed more deeply than in conventional rivalry (Tsuchiya et al., 2006). If the perceptual stability seen in CFS is effectively caused by the continual updating of the "onset state" due to the successive presentation of a new image to one of the two eyes, it is possible that the level of activation achieved by the suppressed image at onset will be overestimated or underestimated relative to that which might have been seen with a sustained rivalry paradigm. This concept of refreshing was raised by Tsuchiya and Koch (2005-supplementary material), however, at the time no distinction had been made between onset rivalry and sustained rivalry. Within this context, the persisting dominance period was conceptualized as a prolongation of a normal sustained rivalry state being repeatedly "refreshed," rather than resetting of the distinct state characteristic of onset rivalry. Further investigation is required to determine how onset rivalry, in which rivaling targets are presented simultaneously, is related to paradigms such as flash suppression and masking, in which stimuli are presented asynchronously.

\section{CONSEQUENCES FOR PAST MODELS AND FUTURE RESEARCH}

Although there is much more research required to determine how various individual differences and stimulus conditions interact at the onset of rivalry, it is clear that the initial period of dominance must be distinguished from subsequent periods in rivalry. This distinction has implications for both past and future research into perceptual rivalry. Firstly, as the normal visual environment is constantly changing due to the dynamic nature of the external scenery and rapid and continuous natural saccadic eye movements (Henderson and Hollingworth, 1998), the mechanisms underlying the first interpretation of an ambiguous visual scene are likely to be most relevant for understanding conscious visual perception in a natural environment. The observation that dominance in rivalry after a saccade appears to be heavily related to the onset bias (Kalisvaart et al., 2011) further suggests that onset rivalry paradigms are likely to provide the greatest insight into how the brain deals with ambiguity in natural viewing conditions.

In contrast, brief presentation paradigms may be less suitable for investigating the alternating periods of dominance that characterize sustained rivalry. As this review has shown, endogenous factors and stimulus features affect dominance differently at onset than during sustained rivalry. Experimental conditions intending to investigate rivalry switching may exhibit different effects depending on the period of rivalry that is examined. Even paradigms that last for several seconds may still be influenced by onset biases, particularly for observers with naturally slower switch rates (Dobbins and Grossmann, 2010). With this caveat in mind, one might consider the possibility that it is the first switch, rather than the first conscious dominant percept, that marks the commencement of traditional, sustained rivalry. Indeed, the underlying mechanisms governing onset dominance appear to be unrelated to the initiation of transitional "suppression waves" that typically characterize a change in dominance (van Ee, 2011).

As a final caution, the literature reviewed here suggests that care is needed when interpreting data using intermittent presentations involving multiple repeated stimulus onsets—such as perceptual memory paradigms or CFS. It is likely that factors specific to onset rivalry may interfere with intermittent presentations aimed at investigating longer-term aspects of perceptual competition. Similarly, effects of past stimulus history are likely to influence onset dominance if testing involves multiple repeated trials.

\section{CONCLUSION}

Perceptual rivalry is a valuable tool for investigating the neural processes underlying perceptual awareness. The complexity in the time course of rivalry can also shed light on the brain's mechanism for dealing with ambiguity in everyday environments. As the average fixation period in natural viewing is approximately $300 \mathrm{~ms}$ (Henderson and Hollingworth, 1998), an individual's initial perceptual experience is likely to be the most relevant in everyday encounters with rivaling visual input. Current data cannot distinguish whether onset and sustained rivalry are determined by completely distinct mechanisms or share mechanisms that are nevertheless influenced by a range of factors in quite distinct ways. For example, dominance at onset appears to be particularly sensitive to early visual factors such as contrast and ocular dominance, while the role of higher cognitive factors is less clear. Additional work is needed to explore the interaction between onset and sustained rivalry in hybrid paradigms like intermittent presentation and continuous flash suppression, which involve repeated onset presentations in rapid succession.

\section{ACKNOWLEDGMENTS}

This work was supported by a National Health Medical Research Council of Australia Career Development Award [\#628590] to Olivia Carter and by grants from an ANR Chaire d'Excellence and NIH EY009258 to Patrick Cavanagh. 


\section{REFERENCES}

Albrecht, J., Jägle, H., Hood, D. C., and Sharpe, L. T. (2002). The multifocal electroretinogram (mfERG) and cone isolating stimuli: variation in Land M-cone driven signals across the retina. J. Vis. 2, 543-558.

Bays, P. M., and Husain, M. (2007). Spatial remapping of the visual world across saccades. Neuroreport 18, 1207-1213.

Blake, R., and Logothetis, N. K. (2002). Visual competition. Nat. Rev. Neurosci. 3, 13-21.

Blake, R., Sobel, K. V., and Gilroy, L. A. (2003). Visual motion retards alternations between conflicting perceptual interpretations. Neuron 39, 869-878.

Blake, R., and Wilson, H. (2011). Binocular vision. Vis. Res. 51, 754-770.

Brascamp, J. W., Knapen, T. H. J., Kanai, R., Noest, A. J., van Ee, R., and van den Berg, A. V. (2008). Multitimescale perceptual history resolves visual ambiguity. PLoS ONE 3, e1497. doi: 10.1371/journal.pone.0001497

Brascamp, J. W., Pearson, J., Blake, R., and van den Berg, A. V. (2009). Intermittent ambiguous stimuli: implicit memory causes periodic perceptual alternations. J. Vis. 9, 3.1-23.

Brascamp, J. W., van Ee, R., Noest, A. J., Jacobs, R. H. A. H., and van den Berg, A. V. (2006). The time course of binocular rivalry reveals a fundamental role of noise. J. Vis. 6, 1244-1256.

Breitmeyer, B. G. (1984). Visual Masking. Oxford: Oxford University Press.

Carrasco, M., Ling, S., and Read, S. (2004). Attention alters appearance. Nat. Neurosci. 7, 308-313.

Carter, O. L., and Cavanagh, P. (2007). Onset rivalry: brief presentation isolates an early independent phase of perceptual competition. PLoS ONE 2, e343. doi: 10.1371/journal.pone. 0000343

Cavanagh, P., Hunt, A. R., Afraz, A., and Rolfs, M. (2010). Visual stability based on remapping of attention pointers. Trends Cogn. Sci. 14, 147-153.

Chen, X., and He, S. (2003). Temporal characteristics of binocular rivalry: visual field asymmetries. Vis. Res. 43 , 2207-2212.

Chong, S. C., and Blake, R. (2006). Exogenous attention and endogenous attention influence initial dominance in binocular rivalry. Vis. Res. 46, 1794-1803.

Chopin, A., and Mamassian, P. (2010). Task usefulness affects perception of rivalrous images. Psychol. Sci. 21, 1886-1893.

Crovitz, H. F., and Lipscomb, D. B. (1963). Dominance of the temporal visual fields at a short duration of stimulation. Am. J. Psychol. 76, 631-637.

Denison, R. N., Piazza, E., and Silver, M. A. (in press). Predictive context influences perceptual selection during binocular rivalry. Front. Hum. Neurosci.

Dobbins, A. C., and Grossmann, J. K. (2010). Asymmetries in perception of 3D orientation. PLoS ONE 5, e9553. doi: 10.1371/journal.pone.0009553

Fox, R., and Herrmann, J. (1967). Stochastic properties of binocular rivalry alternations. Percept. Psychophys. 2, 432-436.

Gray, K. L. H., Adams, W. J., and Garner, M. (2009). The influence of anxiety on the initial selection of emotional faces presented in binocular rivalry. Cognition 113, 105-110.

Haynes, J.-D., Deichmann, R., and Rees, G. (2005). Eye-specific effects of binocular rivalry in the human lateral geniculate nucleus. Nature 438, 496-499.

Henderson, J., and Hollingworth, A. (1998). "Eye movements during scene viewing: an overview," in Eye Guidance in Reading and Scene Perception, ed. G. Underwood (Oxford: Elsevier), 269-293.

Hohwy, J., Roepstorff, A., and Friston, K. (2008). Predictive coding explains binocular rivalry: an epistemological review. Cognition 108, 687-701.

Holcombe, A. O., and Seizova-Cajic, T. (2008). Illusory motion reversals from unambiguous motion with visual, proprioceptive, and tactile stimuli. Vis. Res. 48, 1743-1757.

Hupé, J.-M., and Rubin, N. (2003). The dynamics of bi-stable alternation in ambiguous motion displays: a fresh look at plaids. Vis. Res. 43, 531-548.

Kalisvaart, J. P., Rampersad, S. M., and Goossens, J. (2011). Binocular onset rivalry at the time of saccades and stimulus jumps. PLoS ONE 6, e20017. doi: 10.1371/journal.pone. 0020017

Kaplan, I. T., and Metlay, W. (1964). Light intensity and binocular rivalry. J. Exp. Psychol. 67, 22-26.

Kim, Y.-J., Grabowecky, M., and Suzuki, S. (2006). Stochastic resonance in binocular rivalry. Vis. Res. 46, 392-406.

Klink, P. C., van Ee, R., Nijs, M. M., Brouwer, G. J., Noest, A. J., and van Wezel, R. J. A. (2008). Early interactions between neuronal adaptation and voluntary control determine perceptual choices in bistable vision. J. Vis. 8, 16.11-16.18.

Knapen, T., Brascamp, J., Adams, W. J., and Graf, E. W. (2009). The spatial scale of perceptual memory in ambiguous figure perception. $J$. Vis. 9, 16.11-16.12.

Leat, S. J., and Woodhouse, J. M. (1984). Rivalry with continuous and flashed stimuli as a measure of ocular dominance across the visual field. Perception 13, 351-357.

Lee, S.-H., Blake, R., and Heeger, D. J. (2005). Traveling waves of activity in primary visual cortex during binocular rivalry. Nat. Neurosci. 8, 22-23.

Leopold, D. A., and Logothetis, N. K. (1996). Activity changes in early visual cortex reflect monkeys' percepts during binocular rivalry. Nature 379, 549-553.

Leopold, D. A., Wilke, M., Maier, A., and Logothetis, N. K. (2002). Stable perception of visually ambiguous patterns. Nat. Neurosci. 5, 605-609.

Levelt, W. J. (1967). Note on the distribution of dominance times in binocular rivalry. Br. J. Psychol. 58, 143-145.

Lin, Z., and He, S. (2009). Seeing the invisible: the scope and limits of unconscious processing in binocular rivalry. Prog. Neurobiol. 87, 195-211.

Logothetis, N. K. (1998). Single units and conscious vision. Philos. Trans. R. Soc. Lond. B Biol. Sci. 353, 1801-1818. Long, G. M., and Toppino, T. C. (2004). Enduring interest in perceptual ambiguity: alternating views of reversible figures. Psychol. Bull. 130, 748-768.

Miller, S. M., Gynther, B. D., Heslop, K. R., Liu, G. B., Mitchell, P. B., Ngo, T. T., Pettigrew, J. D., and Geffen, L. B. (2003). Slow binocular rivalry in bipolar disorder. Psychol. Med. 33 , 683-692.

Mitchell, J. F., Stoner, G. R., and Reynolds, J. H. (2004). Object-based attention determines dominance in binocular rivalry. Nature 429, 410-413.

Moreno-Bote, R., Rinzel, J., and Rubin, N. (2007). Noise-induced alternations in an attractor network model of perceptual bistability. J. Neurophysiol. 98, 1125-1139.

Mueller, T. J., and Blake, R. (1989). A fresh look at the temporal dynamics of binocular rivalry. Biol. Cybern. 61, 223-232.

Nagamine, M., Yoshino, A., Yamazaki, M., Obara, M., Sato, S.-I., Takahashi, Y., and Nomura, S. (2007). Accelerated binocular rivalry with anxious personality. Physiol. Behav. 91, 161-165.

Noest, A. J., van Ee, R., Nijs, M. M., and van Wezel, R. J. A. (2007). Percept-choice sequences driven by interrupted ambiguous stimuli: a low-level neural model. J. Vis. 7, 10.

Pastukhov, A., and Braun, J. (2008). A short-term memory of multi-stable perception. J. Vis. 8, 7.1-7.14.
Pearson, J., and Brascamp, J. (2008). Sensory memory for ambiguous vision. Trends Cogn. Sci. 12, 334-341.

Pitts, M., and Britz, J. (2011). Insights from intermittent binocular rivalry and EEG. Front. Hum. Neurosci. 5:107. doi: 10.3389/fnhum. 2011.00107

Pressnitzer, D., and Hupé, J.-M. (2006). Temporal dynamics of auditory and visual bistability reveal common principles of perceptual organization. Curr. Biol. 16, 1351-1357.

Sheth, B., and Pham, T. (2008). How emotional arousal and valence influence access to awareness. Vis. Res. 48 , 2415-2424.

Snyder, J. S., Carter, O. L., Hannon, E. E., and Alain, C. (2009). Adaptation reveals multiple levels of representation in auditory stream segregation. $J$. Exp. Psychol. Hum. Percept. Perform. 35, 1232-1244.

Song, C., and Yao, H. (2009). Duality in binocular rivalry: distinct sensitivity of percept sequence and percept duration to imbalance between monocular stimuli. PLoS ONE 4, e6912. doi: 10.1371/journal. pone. 0006912

Stanley, J., Carter, O., and Forte, J. (2011). Color and luminance influence, but can not explain, binocular rivalry onset bias. PLOS ONE 6, e18978. doi: 10.1371/journal.pone. 0018978

Sterzer, P., and Rees, G. (2008). A neural basis for percept stabilization in binocular rivalry. J. Cogn. Neurosci. 20, 389-399.

Sundareswara, R., and Schrater, P. R. (2008). Perceptual multistability predicted by search model for Bayesian decisions. J. Vis. 8, 12.11-19.

Tong, F., and Engel, S. A. (2001). Interocular rivalry revealed in the human cortical blind-spot representation. Nature 411, 195-199.

Tong, F., Meng, M., and Blake, R. (2006). Neural bases of binocular rivalry. Trends Cogn. Sci. 10, 502-511.

Tsuchiya, N., Chung, J., Eliashiv, D., Adolphs, R., and Mamelak, A. (2011). Visual consciousness tracked with direct intracranial recording from early visual cortex in humans. Nat. Precedings. Available at: http://dx.doi. org/10.1038/npre.2011.6040.1

Tsuchiya, N., and Koch, C. (2005). Continuous flash suppression reduces negative afterimages. Nat. Neurosci. 8, 1096-1101.

Tsuchiya, N., Koch, C., Gilroy, L. A., and Blake, R. (2006). Depth of interocular suppression associated with continuous flash suppression, flash suppression, and binocular rivalry. $J$. Vis. 6, 1068-1078. 
van Ee, R. (2009). Stochastic variations in sensory awareness are driven by noisy neuronal adaptation: evidence from serial correlations in perceptual bistability. J. Opt. Soc. Am. A Opt. Image Sci. Vis. 26, 2612-2622.

van Ee, R. (2011). Percept-switch nucleation in binocular rivalry reveals local adaptation characteristics of early visual processing. J. Vis. 11, 1-12.

Wheatstone, C. (1838). Contributions to the physiology of vision-part the first. On some remarkable, and hitherto unobserved, phenomena of binocular vision. Philos. Trans. R. Soc. Lond. B Biol. Sci. 128, 27.

Wilson, H. R. (2007). Minimal physiological conditions for binocular rivalry and rivalry memory. Vis. Res. 47, 2741-2750.

Wolfe, J. M. (1983). Influence of spatial frequency, luminance, and duration on binocular rivalry and abnormal fusion of briefly presented dichoptic stimuli. Perception 12, 447-456.
Conflict of Interest Statement: The authors declare that the research was conducted in the absence of any commercial or financial relationships that could be construed as a potential conflict of interest.

Received: 01 August 2011; paper pending published: 12 August 2011; accepted: 01 November 2011; published online: 05 December 2011.

Citation: Stanley J, Forte JD, Cavanagh $P$ and Carter $O$ (2011) Onset rivalry: the initial dominance phase is independent of ongoing perceptual alternations. Front. Hum. Neurosci. 5:140. doi: 10.3389/fnhum.2011.00140

Copyright (c) 2011 Stanley, Forte, Cavanagh and Carter. This is an openaccess article subject to a non-exclusive license between the authors and Frontiers Media SA, which permits use, distribution and reproduction in other forums, provided the original authors and source are credited and other Frontiers conditions are complied with. 